\title{
The effect of the Cox-maze procedure for atrial fibrillation concomitant to mitral and tricuspid valve surgery
}

\author{
Niv Ad, MD, Sari D. Holmes, PhD, Paul S. Massimiano, MD, Graciela Pritchard, BS, Lori E. Stone, BS, and \\ Linda Henry, PhD
}

Objectives: Atrial fibrillation (AF) is associated with less favorable outcomes in patients undergoing mitral valve and tricuspid valve surgery. Despite growing evidence on the potential benefits of surgical ablation for AF there is significant variability among surgeons in treatment of AF. The purpose of our study was to assess the effect of the Cox-maze procedure on operative and follow-up outcomes.

\begin{abstract}
Methods: In our prospective study, patients who underwent isolated mitral valve or mitral valve + tricuspid valve surgery without history of $\mathrm{AF}(\mathrm{n}=506)$, with untreated $\mathrm{AF}(\mathrm{n}=75)$, or with Cox-maze procedure $(\mathrm{n}=236)$ were included $(\mathrm{N}=817)$. Sinus rhythm was captured according to Heart Rhythm Society guidelines. Patients who underwent the Cox-maze procedure were propensity score matched to patients without history of $\mathrm{AF}$ resulting in 208 pairs of patients.

Results: Operative outcomes were comparable after propensity score matching (Cox-maze procedure vs no AF) stroke/transient ischemic attack $(0.5 \%$ vs $0.5 \% ; P=1.00)$, renal failure $(2.9 \%$ vs $1.4 \% ; P=.34)$, and operative mortality $(1.4 \%$ vs $1.4 \% ; P=1.00)$. High return to sinus rhythm was documented at 6,12 , and 24 months $(92 \%, 91 \%$, and $86 \%$, respectively) as well as sinus rhythm off antiarrhythmic drugs $(79 \%, 84 \%$, and $82 \%$, respectively). Incidence of embolic stroke in patients who underwent Cox-maze procedure was $1.7 \%$ (4 out of 232 patients) and 5.1 cases per 1000 person-years. No difference in 4-year cumulative survival between propensity score-matched groups $(91.9 \%$ vs $86.9 \%$; log rank, $1.67 ; P=.20)$, but higher for patients who underwent Cox-maze procedure versus patients with untreated AF (hazard ratio, $2.47 ; P=.048$ ). Higher additive European System for Cardiac Operative Risk Evaluation (odds ratio, $1.40 ; P<.001$ ) and limited surgeon experience with Cox-maze procedure (odds ratio, $3.60 ; P<.001$ ) were significant predictors for failure to perform Cox-maze procedure.
\end{abstract}

Conclusions: In our center, $76 \%$ of patients undergoing mitral valve or mitral valve+tricuspid valve surgery experiencing AF underwent concomitant Cox-maze procedure, which is considerably higher than the national average. No increased morbidity was associated with the Cox-maze procedure with the benefit of very low thromboembolic rate. These results suggest the need for performance-based education for AF surgical ablation to achieve optimal outcomes. (J Thorac Cardiovasc Surg 2013;146:1426-35)

The prevalence of degenerative valve disease has increased during the past 20 years, namely aortic stenosis and mitral regurgitation. The increase in the prevalence of degenerative valvular disease is attributed to the current longevity of life-older age is significantly associated with the development of both aortic stenosis and mitral regurgitation necessitating surgical repair or replacement. ${ }^{1}$

In addition, approximately $40 \%$ to $50 \%$ of patients undergoing mitral valve (MV) surgery have significant history of atrial fibrillation. ${ }^{1-3}$ These patients will usually

From the Inova Heart and Vascular Institute, Falls Church, Va.

Disclosures: Authors have nothing to disclose with regard to commercial support.

Read at the 93rd Annual Meeting of The American Association for Thoracic Surgery, Minneapolis, Minnesota, May 4-8, 2013.

Received for publication May 3, 2013; revisions received July 22, 2013; accepted for publication Aug 1, 2013; available ahead of print Sept 30, 2013.

Address for reprints: Niv Ad, MD, Inova Heart and Vascular Institute, 3300 Gallows Rd, Falls Church, VA 22042 (E-mail: Niv.Ad@inova.org).

0022-5223/\$36.00

Copyright (c) 2013 by The American Association for Thoracic Surgery

http://dx.doi.org/10.1016/j.jtcvs.2013.08.013 remain in atrial fibrillation with low rates of conversion to sinus rhythm following a successful MV surgery if a surgical ablation procedure is not performed. ${ }^{4-6}$

The significance of not treating atrial fibrillation at the time of surgery is that these patients have been found to have less favorable early and late outcomes following their MV surgery with or without tricuspid valve (TV) surgery. ${ }^{6-8}$ Atrial fibrillation has also been found to be an independent, significant predictor for long-term mortality. ${ }^{9}$ The potential benefits as well as the safety and efficacy of a surgical ablation procedure for atrial fibrillation during MV operations are well documented. However, there is a notable variability among surgeons in whether or not to perform an ablation procedure and how the procedure should be performed. . $^{8,10,11}$ The purpose of our study was to determine the effect of the Cox-maze III/IV procedure performed in conjunction with MV or MV+TV surgery on outcomes as well as determine the variables associated with nonperformance of the Cox-maze procedure for patients presenting with atrial fibrillation. 


\section{Abbreviations and Acronyms \\ EuroSCORE $=$ Eurpean System for Cardiac Operative Risk Evaluation

$\begin{array}{ll}\text { HRQL } & =\text { health-related quality of life } \\ \text { MV } & =\text { mitral valve } \\ \text { NSR } & =\text { normal sinus rhythm } \\ \text { PSM } & =\text { propensity score matching } \\ \text { TV } & =\text { tricuspid valve }\end{array}$

\section{METHODS}

This was a single-center cohort study in which all data were collected prospectively for surgery occurring between January 2005 and January 2013. This study was approved by the institutional review board (Nos. 06.022 and 06.037) with patient consent waived. Patients who underwent an MV procedure with or without a TV procedure were examined $(\mathrm{N}=817)$. Patients were divided into 3 groups based on presence and management of atrial fibrillation, including: patients without a history of atrial fibrillation; that is, normal sinus rhythm (NSR) $(\mathrm{n}=506)$, patients with a history of atrial fibrillation and a concomitant Cox-maze procedure for atrial fibrillation $(\mathrm{n}=236)$, and patients with a history of atrial fibrillation not addressed during MV surgery (ie, untreated atrial fibrillation) $(n=75)$. History of preoperative atrial fibrillation was determined through our local Society of Thoracic Surgeons database and type of atrial fibrillation was determined according to Heart Rhythm Society guidelines.

Detailed follow-up data was collected for patients undergoing Cox-maze procedure as part of our unique atrial fibrillation registry through mailed surveys and medical record review (mean follow-up, $40.2 \pm 28.1$ months). Rhythm status for patients who underwent a surgical ablation procedure was determined according to the Heart Rhythm Society guidelines and verified by electrocardiogram and 24-hour Holter monitor at the time points of 6,12 , and 24 months and then yearly thereafter. The Heart Rhythm Society definition of success (ie, all documented atrial arrhythmias $>30$ seconds are considered a failure) was used to determine the return to sinus rhythm rate at 6,12 , and 24 months. ${ }^{12}$ Anticoagulation status was also collected at the follow-up time points and the clinical indication was determined (ie, history of a clotting disorder, deep vein thrombosis, pulmonary emboli, mechanical valves, and continual atrial arrhythmia) or not clinically indicated (ie, no indications for anticoagulation). All patients were followed and treated using our follow-up atrial arrhythmia control protocol. ${ }^{13}$ In addition, all patients who were reported to be in sinus rhythm off antiarrhythmic drugs without a pacemaker were offered 5- to 7-day mobile cardiac outpatient telemetry monitoring (CardioNet Inc, Conshohocken, Pa) at 6 and 24 months.

Patients with untreated atrial fibrillation (mean follow-up $35.3 \pm 27.1$ months) and without history of atrial fibrillation (mean follow-up $42.7 \pm$ 29.4 months) were followed prospectively for health-related quality of life through mailed surveys and survival postdischarge through the Social Security Death Index and National Death Index. Data from the Society of Thoracic Surgeons was available on all patients as well and definitions from this database were used for history of atrial fibrillation, preoperative characteristics, and perioperative outcomes.

\section{Operative Approach}

Multiple surgeons performed the complete Cox-maze III/IV lesion set in all patients, as described previously. ${ }^{14,15}$ The energy source used was cryothermia only (Medtronic, Minneapolis, Minn) in 65\% of patients and combination of cryothermia and bipolar radiofrequency (AtriCure Inc, West Chester, Ohio) in $35 \%$ of patients. The left atrial appendage was amputated and then oversewn in the midsternotomy patients.
However, in the minimally invasive procedure, the left atrial appendage was excluded by endocardial suturing.

\section{Health-Related Quality of Life (HRQL)}

HRQL was evaluated at baseline and follow-up using the Short-Form 12. This is a reliable and well-validated instrument for use across diverse disease populations, including cardiac surgery patients, and is easy to administer being particularly adept for use in self-report situations. ${ }^{16} \mathrm{~A}$ higher score indicates better HRQL and can be compared against age group norms. To capture patient perception of atrial fibrillation symptoms, we administered the Atrial Fibrillation Symptom Checklist: Frequency and Severity (version 3) to Cox-maze patients. ${ }^{17}$ This survey consists of 16 symptom items. Higher scores indicate more atrial fibrillation symptoms and a higher degree of severity when experiencing the symptom.

\section{Statistical Analysis}

Continuous data are presented as mean \pm standard deviation and categorical data are presented as frequency (percent) unless otherwise noted. Patient groups were compared using $\chi^{2}$ or Fisher exact test for preoperative and postoperative categorical variables and Student independent samples $t$ test or Mann-Whitney $U$ test for continuous measures as appropriate based on parametric test assumptions. Statistical significance was considered $P<.05,2$-tailed. All analyses were conducted using SPSS version 17.0 (SPSS Inc, Chicago, Ill) or R version 2.10.1 (The R Foundation for Statistical Computing).

In an effort to simulate randomization in this observational study, propensity score matching was conducted between the group without history of atrial fibrillation and the group with concomitant Cox-maze for atrial fibrillation. The main purpose of these analyses was to examine if the addition of the Cox-maze procedure could allow patients with preoperative atrial fibrillation to experience comparable outcomes as similar patients without a history of atrial fibrillation. Propensity score matching (PSM) was conducted using the MatchIt package within $\mathrm{R}$ to improve covariate balance between the 2 groups. Propensity score was estimated via logistic model and matched between the groups within a caliper of 0.25 propensity score standard deviations. The covariates used to create the propensity score were based on clinical relevance and sample characteristics, including age, gender, diabetes, hypertension, congestive heart failure, elective status, chronic pulmonary disease, ejection fraction (\%), additive European System for Cardiac Operative Risk Evaluation (EuroSCORE) I, previous cardiac surgery, and preoperative creatinine level. After matching, covariate balance was improved for all factors (Figure 1) and the sample remaining included 416 patients (208 pairs), which was used for all analyses described as matched or PSM.

Kaplan-Meier analysis was used to compare the 2 matched groups on 4-year cumulative survival. Additionally, unmatched Cox-maze patients $(\mathrm{n}=236)$ and the subset of patients with untreated atrial fibrillation $(n=75)$ were compared via Kaplan-Meier analysis to determine if any differences in 4-year cumulative survival existed between these 2 groups with history of atrial fibrillation. Subsequently, multivariate Cox proportional hazards regression analysis was conducted with the Cox-maze and untreated atrial fibrillation groups to determine predictors of 4-year survival, including age, gender, ejection fraction, hypertension, peripheral vascular disease, congestive heart failure, chronic pulmonary disease, diabetes, tricuspid valve procedure (yes or no), cardiopulmonary bypass time, and surgery groups.

In the Cox-maze group, return to sinus rhythm, incidence of embolic stroke, and anticoagulation treatment were assessed via descriptive statistics. Also, predictors for atrial fibrillation at 6, 12, and 24 months following the Cox-maze were evaluated via multivariate logistic regression, including: age, gender, ejection fraction, additive EuroSCORE, previous cardioversion or catheter ablation, left atrial size (in centimeters), and duration of atrial fibrillation before surgery (in years). Changes in HRQL and atrial fibrillation symptom burden from pre- to post-surgery were evaluated 
Distribution of Propensity Scores

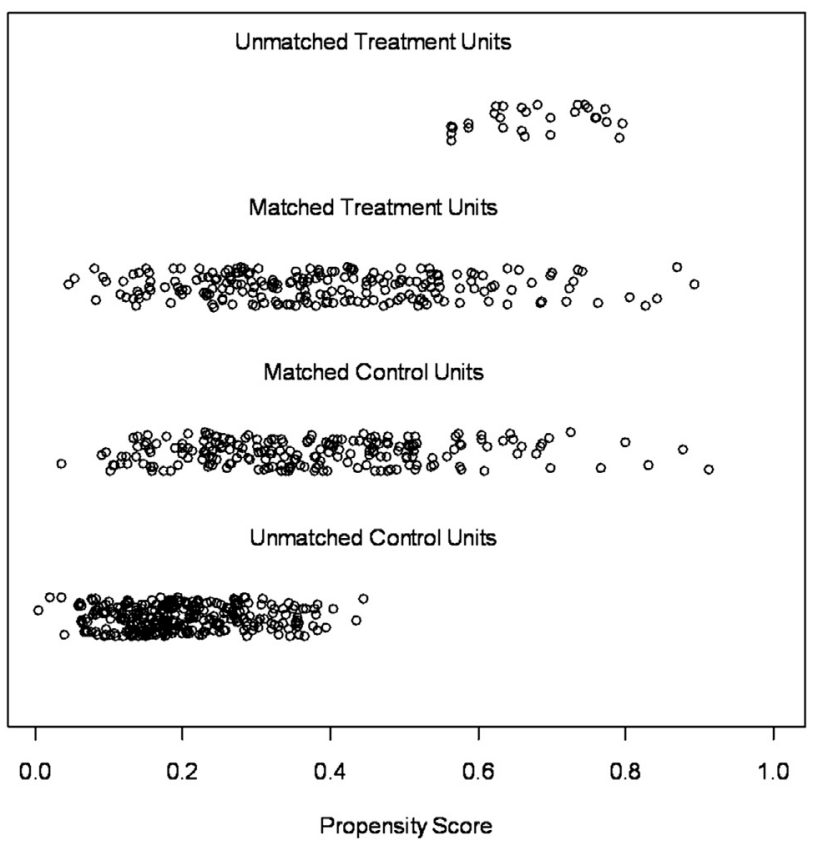

FIGURE 1. Jitter plot illustrating balance achieved from propensity score matching the treatment (Cox-maze procedure) and control (normal sinus rhythm) groups.

via paired samples $t$ tests and differences between sample HRQL scores and HRQL norms were evaluated via independent samples $t$ tests. Lastly, exploratory multivariate logistic regression was conducted to determine the significant predictors for failure to perform a concomitant Cox-maze procedure. This analysis utilized only unmatched patients with a history of atrial fibrillation, Cox-maze procedure (yes or no) served as the dependent variable, and independent variables included age, gender, additive EuroSCORE, diabetes, congestive heart failure, chronic pulmonary disease, emergent status, and surgeon experience ( $\geq 50$ surgical ablation for atrial fibrillation cases vs $<50$ surgical ablation for atrial fibrillation cases).

\section{RESULTS \\ Patient Characteristics}

Patients presenting to surgery with atrial fibrillation were older ( $64.4 \pm 13.3$ years vs $57.4 \pm 12.8$ years; $P<.001)$, had lower ejection fraction $(54.5 \% \pm 11.6 \%$ vs $59.9 \% \pm$ $8.0 \% ; P<.001)$, higher additive EuroSCORE $(7.0 \pm 3.5$ vs $4.8 \pm 3.1 ; P<.001)$, and there was a greater proportion of women $(54 \%$ vs $41 \% ; P<.001)$ compared with patients who presented to surgery in sinus rhythm. Within the atrial fibrillation group, patients who received the Cox-maze procedure were younger $(63.6 \pm 13.2$ years vs $67.1 \pm 13.4$ years; $P=.049)$, had higher ejection fraction $(55.8 \% \pm 10.5 \% \mathrm{vs}$ $50.5 \% \pm 14.1 \% ; P=.003$ ), and lower additive EuroSCORE $(6.1 \pm 2.9$ vs $9.8 \pm 3.7 ; P<.001)$ compared with the untreated atrial fibrillation group. The Cox-maze group did not differ from the untreated atrial fibrillation group in nonparoxysmal atrial fibrillation type $(85 \%$ vs $81 \% ; P=.47)$, duration of atrial fibrillation ( $38.7 \pm 62.8$ months vs $46.8 \pm 60.2$ months;
$P=.44)$, or left atrial size $(5.3 \pm 1.0 \mathrm{~cm}$ vs $5.0 \pm 1.2 \mathrm{~cm}$; $P=.06)$.

Before matching, compared with patients who presented to surgery in sinus rhythm, patients with atrial fibrillation who underwent the Cox-maze procedure were significantly older ( $63.6 \pm 13.2$ years vs $57.4 \pm 12.8$ years; $P<.001)$, had lower ejection fraction $(55.8 \% \pm 10.5 \%$ vs $59.9 \% \pm$ $8.0 \% ; P<.001)$ and were more likely to be a woman $(56 \%$ vs $41 \% ; P<.001)$. They also differed on other clinical characteristics (Table 1), such as higher prevalence of hypertension $(61 \%$ vs $49 \% ; P=.003)$, congestive heart failure $(51 \%$ vs $29 \% ; P<.001)$, previous cardiac surgery $(15 \%$ vs $9 \% ; P=.01)$, and higher additive EuroSCORE I $(6.1 \pm 2.9$ vs $4.8 \pm 3.1 ; P<.001)$ and EuroSCORE II $(5.0 \% \pm 6.4 \%$ vs $2.5 \% \pm 5.4 \% ; P<.001)$. After PSM, the groups were well matched on preoperative characteristics (Table 1).

In these 2 groups with concomitant TV surgery $(\mathrm{n}=112)$ only 1 patient had TV replacement. For MV replacements, bioprosthesis was used in $73 \%$ of patients and mechanical valves were used in $27 \%$ of patients. In the Cox-maze group with MV replacements, $50 \%$ were indicated for rheumatic heart disease. In 4 patients the procedure was performed as a redo with 2 previous MV repairs and 2 previous MV replacements.

\section{Operative Outcomes and Survival}

In the study period $76 \%$ of patients with history of atrial fibrillation (236 out of 311 patients) underwent the Coxmaze combined either with MV surgery alone (164 out of 236 patients; $69 \%$ ) or together with a TV procedure (72 out of 236 patients; $31 \%$ ). Operative outcomes of the 3 unmatched groups of patients are presented in Table 2. There were no differences between the patients who presented to surgery with NSR and those who underwent the Cox-maze procedure on morbidities, although median intensive care unit stay and total length of stay were significantly longer in the Cox-maze group $(P \mathrm{~s}<.001)$. Compared with the Cox-maze group, the group with untreated atrial fibrillation did experience more prolonged ventilation ( $>24$ hours; $28 \%$ vs $7 \% ; P<.001)$, pneumonia $(15 \%$ vs $3 \% ; P<.001)$, longer median length of stay ( 9 days [interquartile range, 6-15 days] vs 6 days [interquartile range, 5-10 days]; $P=.005$ ), but fewer readmissions within 30 days $(4 \%$ vs $12 \%$; $P=.048)$. The majority of readmissions for the Cox-maze and NSR groups were for pericardial effusion, atrial arrhythmia, or anticoagulation-related issues. In the untreated atrial fibrillation group, the indications for readmission were similar with the majority of patients admitted for pericardial effusion and atrial arrhythmia.

After propensity score matching (Figure 1), operative outcomes remained comparable for the matched groups (Cox-maze vs NSR patients), including stroke/transient ischemic attack $(0.5 \%$ vs $0.5 \% ; P=1.00)$, prolonged ventilation $>24$ hours $(8 \%$ vs $7 \% ; P=.86)$, renal failure 
TABLE 1. Preoperative patient characteristics for nonmatched normal sinus rhythm (NSR) and Cox-maze procedure patient groups and propensity score matched (PSM) NSR and Cox-maze procedure patient groups

\begin{tabular}{|c|c|c|c|c|}
\hline & \multicolumn{2}{|c|}{ Nonmatched MV/TV } & \multicolumn{2}{|c|}{ PSM MV/TV } \\
\hline & $\operatorname{NSR}(n=506)$ & Cox-maze $(n=236)$ & $\operatorname{NSR}(n=208)$ & Cox-maze $(n=208)$ \\
\hline Age, $*$ y & $57.4 \pm 12.8$ & $63.6 \pm 13.2$ & $62.0 \pm 12.2$ & $62.6 \pm 13.4$ \\
\hline Female* & $207(41)$ & $132(56)$ & $115(55)$ & $112(54)$ \\
\hline Diabetes & $43(8)$ & $19(8)$ & $17(8)$ & $17(8)$ \\
\hline Hypertension* & $248(49)$ & $143(61)$ & $123(59)$ & $121(58)$ \\
\hline Congestive heart failure* & $144(28)$ & $121(51)$ & $91(44)$ & $93(45)$ \\
\hline Ejection fraction, $* \%$ & $59.9 \pm 8.0$ & $55.8 \pm 10.5$ & $57.4 \pm 8.8$ & $56.7 \pm 10.0$ \\
\hline Elective status & $444(88)$ & $201(85)$ & $179(86)$ & $180(87)$ \\
\hline Previous cerebrovascular accident & $31(6)$ & $17(7)$ & $14(7)$ & $14(7)$ \\
\hline Chronic pulmonary disease & $65(13)$ & $35(15)$ & $28(14)$ & $28(14)$ \\
\hline Preoperative creatinine level & $1.1 \pm 0.9$ & $1.0 \pm 0.7$ & $1.1 \pm 0.5$ & $1.0 \pm 0.7$ \\
\hline Peripheral vascular disease & $19(4)$ & $13(6)$ & $13(6)$ & $9(4)$ \\
\hline Previous cardiac surgery* & $44(9)$ & $35(15)$ & $35(17)$ & $28(14)$ \\
\hline MV repair* & $390(77)$ & $151(64)$ & $142(68)$ & $135(65)$ \\
\hline MV replacement* & $116(23)$ & $85(36)$ & $66(32)$ & $73(35)$ \\
\hline Additive EuroSCORE I* & $4.8 \pm 3.1$ & $6.1 \pm 2.9$ & $6.0 \pm 3.3$ & $5.8 \pm 2.6$ \\
\hline Concomitant TV surgery*, $†$ & $40(8)$ & $72(31)$ & $20(10)$ & $60(29)$ \\
\hline Cardiopulmonary bypass time, ${ }^{*}, \dagger \min$ & $130.9 \pm 42.9$ & $173.0 \pm 45.1$ & $129.4 \pm 45.8$ & $174.1 \pm 45.2$ \\
\hline Crossclamp time, ${ }^{*}, \dagger \min$ & $85.0 \pm 28.8$ & $107.4 \pm 32.7$ & $83.1 \pm 29.9$ & $108.4 \pm 33.0$ \\
\hline EuroSCORE II, $* \%$ & $2.5 \pm 5.4$ & $5.0 \pm 6.4$ & $3.8 \pm 7.3$ & $4.1 \pm 4.1$ \\
\hline
\end{tabular}

Data are presented as mean \pm standard deviation or n (\%). MV, Mitral valve; TV, tricuspid valve; PSM, propensity score matched; NSR, normal sinus rhythm; EuroSCORE, European System for Cardiac Operative Risk Evaluation. *Significant difference in factor between nonmatched NSR and Cox-maze groups $(P<.05)$. $\nmid$ Significant difference in factor between matched NSR and Cox-maze groups $(P<.05)$.

$(2.9 \%$ vs $1.4 \% ; P=.34)$, and operative mortality $(1.4 \%$ vs $1.4 \% ; P=1.00$ ) (Table 3 ). The Cox-maze group did have a significantly longer median intensive care unit stay (47.1 hours [interquartile range, 23.8-85.6 hours] vs 21.2 hours [interquartile range, 8.5-43.1 hours]; $P<.001)$ and total length of stay ( 6 days [interquartile range, 5-10 days] vs 4 days [interquartile range, 3-6 days]; $P<.001$ ).

No difference was found in 4-year cumulative survival between the matched groups $(91.9 \%$ [Cox-maze] vs $86.9 \%$ [NSR]; log rank, 1.67; $P=.20$ ) (Figure 2). Compared with the untreated atrial fibrillation patients, 4-year cumulative survival was significantly higher for unmatched Cox-maze patients $(90.7 \%$ vs $78.3 \%$; log rank, 9.23; $P=.002$ ). After multivariate adjustment for clinical covariates, 4-year survival in the untreated atrial fibrillation patients remained significantly lower compared with the Cox-maze group (hazard ratio, $2.47 ; P=.048$ ) (Figure 3). The only other significant predictor of survival in this model was chronic pulmonary disease (hazard ratio, $3.35 ; P=.005)$.

In addition, physical HRQL scores appeared to increase to a greater extent in the matched Cox-maze group compared with the matched NSR patients (8-point vs 4-point improvement), although this difference did not reach statistical

TABLE 2. Postoperative morbidity comparison between unmatched patients without atrial fibrillation (AF) history (ie, normal sinus rhythm [NSR]), patients with concomitant Cox-maze procedure and patients with untreated AF

\begin{tabular}{lccc}
\hline & NSR $(\mathbf{n}=\mathbf{5 0 6})$ & Cox-maze $(\mathbf{n}=\mathbf{2 3 6})$ & Untreated AF (n= 75) \\
\hline Stroke/transient inschemic attack & $3(0.6)$ & $1(0.4)$ & $2(3)$ \\
Perioperative myocardial infarction & 0 & 0 & 0 \\
Prolonged ventilation*,$\dagger$ & $33(7)$ & $17(7)$ & $21(28)$ \\
Pneumonia $\dagger$ & $7(1.4)$ & $7(3)$ & $11(15)$ \\
Deep sternal wound infection & 0 & 0 & 0 \\
Postoperative renal failure & $6(1.2)$ & $7(3)$ & $4(5)$ \\
Renal failure requiring dialysis & $3(0.6)$ & $4(1.7)$ & $2(2.7)$ \\
Reoperation for bleeding & $10(2)$ & $48(25-94.8)$ & $3(4)$ \\
Length of intensive care unit stay, $\dagger$ h & $17.9(9.1-34.6)$ & $6(5-10)$ & $62.3(25-163.5)$ \\
Length of stay, $\dagger, \dagger \mathrm{d}$ & $3(2-6)$ & $28(12)$ & $9(6-15)$ \\
Readmissions within $30 \mathrm{~d} \ddagger$ & $50(10)$ & $5(2)$ & $3(4)$ \\
Operative death & $5(1)$ & $5(7)$ & \\
\hline
\end{tabular}

Data are presented as $\mathrm{n}(\%)$ or median (range). $N S R$, Normal sinus rhythm; $A F$, atrial fibrillation. * $>24$ hours. $\dagger$ Significant difference in factor between nonmatched Cox-maze and untreated AF groups $(P<.05)$. †̦Significant difference in factor between nonmatched Cox-maze and NSR groups $(P<.05)$. 
TABLE 3. Early outcomes for matched patients without atrial fibrillation history (ie, normal sinus rhythm [NSR]) and patients with concomitant Cox-maze procedure

\begin{tabular}{|c|c|c|c|}
\hline & $\begin{array}{c}\text { NSR } \\
(\mathrm{n}=\mathbf{2 0 8}) \\
\end{array}$ & $\begin{array}{l}\text { Cox-maze } \\
(\mathrm{n}=\mathbf{2 0 8})\end{array}$ & $P$-value \\
\hline Stroke/transient ischemic attack & $1(0.5)$ & $1(0.5)$ & 1.00 \\
\hline $\begin{array}{l}\text { Perioperative myocardial } \\
\text { infarction }\end{array}$ & 0 & 0 & - \\
\hline Prolonged ventilation* & $15(7)$ & $16(8)$ & 1.00 \\
\hline Pneumonia & $3(1.4)$ & $7(3)$ & .34 \\
\hline Deep sternal wound infection & 0 & 0 & - \\
\hline Postoperative renal failure & $3(1.4)$ & $6(2.9)$ & .50 \\
\hline Renal failure requiring dialysis & $2(1)$ & $4(2)$ & .69 \\
\hline Reoperation for bleeding & $4(2)$ & $6(3)$ & .75 \\
\hline $\begin{array}{l}\text { Length of intensive care } \\
\text { unit stay, } \dagger \mathrm{h}\end{array}$ & $21.2(8.5-43.1)$ & $47.1(23.8-85.6)$ & $<.001$ \\
\hline Length of stay, $\dagger d$ & $4(3-6)$ & $6(5-10)$ & $<.001$ \\
\hline Readmissions within $30 \mathrm{~d}$ & $22(11)$ & $26(13)$ & .65 \\
\hline$\underline{\text { Operative death }} \underset{\ddagger}{\ddagger}$ & $3(1.4)$ & $3(1.4)$ & 1.00 \\
\hline
\end{tabular}

significance $(F=2.9 ; P=.09)$ due to the small percent of matched patients with HRQL data and only $39 \%$ observed power. There was no difference in mental HRQL improvements by matched groups $(F=0.2 ; P=.63)$.

\section{The Cox-Maze III/IV Group Outcomes}

At discharge, 19 patients (8\%) had an atrial arrhythmia (18 with atrial fibrillation and 1 with typical atrial flutter). Pacemaker for sinus node dysfunction was implanted in 3 patients $(1.3 \%)$. The return to sinus rhythm was documented at $6(92 \%, 171$ out of 185 patients), $12(91 \%$, 141 out of 155 patients), and 24 months post-surgery

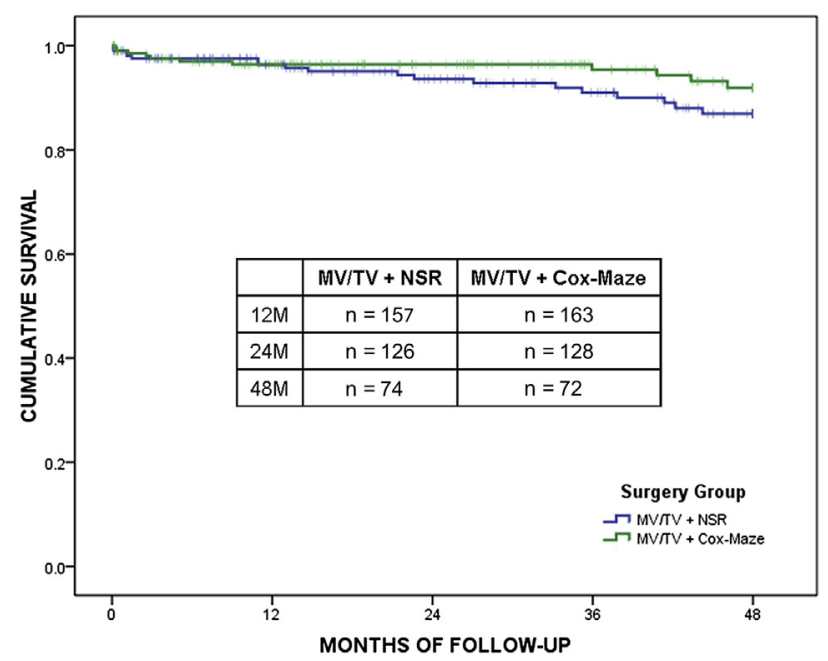

FIGURE 2. Kaplan-Meier survival curves demonstrating 4-year cumulative survival for propensity score-matched patients $(\mathrm{n}=416) . M$, Months; $M V$, mitral valve; $T V$, tricuspid valve; $N S R$, normal sinus rhythm.

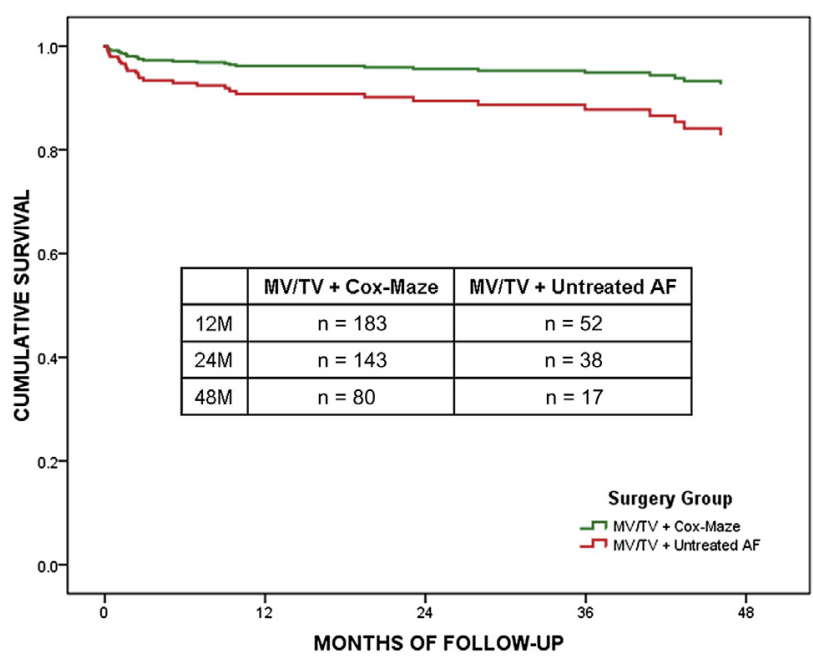

FIGURE 3. Outcome of the Cox proportional hazards regression demonstrating 4-year cumulative survival for mitral valve $(M V)$ patients with atrial fibrillation $(A F)$ who underwent a concomitant Cox-maze procedure $(\mathrm{n}=236)$ and those who did not $(\mathrm{n}=75) . M$, Months; $T V$, tricuspid valve.

( $86 \% ; 85$ out of 96 patients). Return to sinus rhythm off class I/III anti-arrhythmic drugs at 6,12 , and 24 months was $79 \%$ (144 out of 183 patients), $84 \%$ (130 out of 155 patients), and $82 \%$ (79 out of 96 patients), respectively. Predictors of atrial fibrillation at 12 months included higher operative risk and patient complexity, as reflected by the additive EuroSCORE (odds ratio, 1.31; 95\% confidence interval, 1.004-1.72; $P=.047)$ and longer duration of atrial fibrillation in years (odds ratio, $1.11 ; 95 \%$ confidence interval, $1.02-1.21 ; P=.02$ ), but not left atrial size (odds ratio, $1.67 ; 95 \%$ confidence interval, $0.89-3.11 ; P=.11)$. Only longer duration of atrial fibrillation in years (odds ratio, $1.25 ; 95 \%$ confidence interval, $1.07-1.46 ; P=.004$ ) was a significant predictor of atrial fibrillation at 24 months. Patients found to be in sinus rhythm and off class I/III anti-arrhythmic drugs at 6 and 24 months were offered 5- to 7-day rhythm monitoring with compliance of $60 \%$ and $35 \%$, respectively. Return to NSR per 5- to 7-day rhythm monitoring was $92 \%$ at 6 months ( 72 out of 78 patients) and $89 \%$ at 24 months ( 25 out of 28 patients).

Ninety-one percent of Cox-maze patients were discharged from the hospital taking warfarin. At 12 months, $25 \%$ of patients remained taking warfarin ( 37 out of $150 \mathrm{pa}-$ tients) and were taking it for clinical indications unrelated to atrial arrhythmia (ie, deep vein thrombosis or pulmonary embolism), including 10 patients with mechanical valves. In the remaining patients $(\mathrm{n}=113)$, the majority were not receiving warfarin treatment by 12 months $(84 \%)$ leaving only $16 \%$ taking warfarin. Although a little more than $90 \%$ of this $16 \%$ of patients were documented to be in sinus rhythm, warfarin was not stopped by their cardiologist. In mean follow-up of $40.2 \pm 28.1$ months, the incidence of embolic stroke in Cox-maze patients following discharge 
from the hospital was very low $(1.7 \%$; 4 out of 232 patients; 5.1 cases per 1000 person-years; $0.5 \%$ annual stroke risk). At the time of stroke, 2 patients were taking warfarin and 3 of 4 were in sinus rhythm. In addition, 3 other patients experienced transient ischemic attack during the same length of follow-up (1.3\%, 3 out of 232 patients; 3.8 cases per 1000 person-years; $0.4 \%$ annual transient ischemic attack risk). At the time of transient ischemic attack, 2 patients were taking warfarin and all 3 patients were in sinus rhythm.

Baseline and 12 month assessment of HRQL was completed in 97 patients following Cox-maze procedure combined with MV with or without TV surgery. Significant improvement was found in physical HRQL scores from before surgery to 12 months post-surgery (40.7-48.3; $t=6.2 ; P<.001)$. Baseline physical HRQL scores were significantly lower than age norms $(t=6.2 ; P<.001)$, but by 12 months these scores reached similar levels to age norms $(t=1.4 ; P=.15)$. Improvement in mental HRQL scores from before surgery to 12 months post-surgery did not reach statistical significance $(52.0-54.1 ; t=1.7$; $P=.09)$. However, 12-month mental HRQL scores significantly surpassed those of age norms $(t=3.6 ; P<.001)$. Using the Atrial Fibrillation Symptom Checklist revealed that the frequency of atrial fibrillation-specific symptoms declined significantly in this group by 12 months $(\mathrm{n}=32$; $19.7-9.4 ; t=-5.0 ; P<.001)$, as did severity of atrial fibrillation symptoms (17.1-9.2; $t=-4.7 ; P<.001)$. Lastly, changes in atrial fibrillation symptom frequency $(\rho=-0.46 ; P=.01)$ and severity $(\rho=-0.47 ; P=.01)$ were significantly correlated with changes in physical HRQL score.

\section{Predicting Addition of Cox-Maze Procedure}

In MV+TV patients who presented with history of atrial fibrillation, the multivariate logistic regression model significantly predicted addition of the Cox-maze procedure $\left(\chi^{2}, 114.93 ; P<.001\right)$. In this model, higher additive EuroSCORE (odds ratio, 1.40; 95\% confidence interval, 1.24$1.57 ; P<.001)$ and limited surgeon experience with surgical ablation for atrial fibrillation at the time of surgery (odds ratio, 3.60; 95\% confidence interval, 1.85-7.01; $P<.001$ ) were found to be significant in predicting not performing the Cox-maze procedure concomitantly with MV and TV surgery. Each 1-point increase in additive EuroSCORE was associated with $40 \%$ greater odds of not receiving a Cox-maze procedure. Using the predicted probability from this model, the area under the curve was 0.86 , indicating the model demonstrated a high level of accuracy in discriminating patients who did and did not receive the Cox-maze procedure.

\section{DISCUSSION}

In our center $76 \%$ of patients who had MV or MV+TV surgeries while experiencing atrial fibrillation underwent a concomitant Cox-maze procedure performed by multiple surgeons, indicating higher ablation rates compared to reports from the Society of Thoracic Surgeons. ${ }^{2,18}$ No increased morbidity was associated with the addition of the Cox-maze procedure and excellent survival was achieved especially when compared with MV patients who did not have their atrial fibrillation treated.

Our results are comparable to several other reports that were published. Bogachev-Prokophiev and colleagues ${ }^{19}$ reported on 47 patients who underwent a bipolar left sided ablation procedure with either mitral valve repair $(n=5)$ or replacement $(n=42)$ and were monitored by a subcutaneous continuous monitor. At 12 months they found that $65.2 \%(\mathrm{n}=30)$ of patients had no atrial fibrillation, $6.5 \%(\mathrm{n}=3)$ of patients had experienced atrial flutter ( 1 atypical flutter and 2 typical flutter) and successfully underwent catheter ablation, and $27.7 \%(\mathrm{n}=13)$ experienced atrial fibrillation with a burden $>0.5 \%$.

Ghavidel and colleagues ${ }^{20}$ used nitrous-based cryothermia energy on a group $(\mathrm{n}=90)$ who underwent surgical ablation $(n=65$ pulmonary vein isolation; $n=25$ biatrial Cox-maze) at the same time as MV surgery. The investigators found that $65.5 \%$ of patients were in sinus rhythm at 12 months with left atrial size $>6 \mathrm{~cm}$ as the only predictor of failure. It was concluded that the use of cryothermia was safe and cost-effective and added only minimal time to the surgery (10 minutes for the pulmonary vein isolation and 20 minutes for the full Cox-maze procedure).

Several studies demonstrated that patients with MV disease and atrial fibrillation who undergo surgical correction of the valve disease, but not for atrial fibrillation have poorer shortand long-term outcomes than patients who come to surgery with MV disease and are in sinus rhythm. ${ }^{21,22}$ In addition, atrial fibrillation was found to be an independent significant predictor for long-term mortality. ${ }^{9}$ The effect of preoperative atrial fibrillation on patients undergoing MV, coronary artery bypass graft, and aortic valve surgery was studied by Ngaage and colleagues ${ }^{21-23}$ and it was determined that preoperative atrial fibrillation was associated with increased morbidity and decreased survival if not corrected. In our study, we found that survival up to 4 years for patients following a concomitant Cox-maze procedure in MV and MV+TV was comparable to similar patients who did not present to surgery with history of atrial fibrillation and did not require a Coxmaze procedure. This finding suggests that by restoring sinus rhythm in a relatively high number of patients with atrial fibrillation undergoing MV and TV surgeries survival benefits may be expected. In addition, the survival of Cox-maze patients in our sample was significantly improved compared with patients with untreated atrial fibrillation. Although we conducted these analyses adjusting for fundamental differences between the atrial fibrillation groups, it is possible that selection bias in performing the Cox-maze procedure still influences this finding. Therefore, the true nature of survival outcomes in surgically treated and untreated atrial fibrillation 
patients with MV or MV+TV disease would need to be addressed through a prospective randomized controlled trial.

The performance of the Cox-maze procedure, the high rate of sinus rhythm and the elimination of the left atrial appendage may have an important effect on risk reduction of thromboembolic and bleeding events. The documented success rate using the Heart Rhythm Society definitions is acceptable even when long-term monitoring was used. Interestingly, the compliance of patients with long-term monitoring was rather low. The reasons for not wearing a monitor for 5 to 7 days were associated with added cost to the patients due to insurance coverage and not wanting to be bothered for a week by a device with no perceived benefit or improved outcome.

In our follow-up we found that about $25 \%$ of patients had an indication for anticoagulation treatment unrelated to atrial arrhythmia. These findings are not surprising; however, it should be emphasized that the Cox-maze procedure is still warranted for these patients due to the expected improved survival and decreased risk of thromboembolic events. $^{4,7-9}$ In our study, we found that for Cox-maze patients, $91 \%$ were discharged from the hospital taking warfarin, but by 12 months following the Cox-maze surgery, the majority $(84 \%)$ of patients eligible to be off anticoagulation treatment had stopped taking anticoagulants. The stroke rate found for patients after the Cox-maze procedure (5.1 cases per 1000 person-years) was comparable to other surgical ablation centers. The rate was also lower than would be expected when calculated using data provided by the National Registry of Atrial Fibrillation (34.5 cases per 1000 person-years), adjusted for distribution of CHADS score in our sample. ${ }^{24-26}$ These findings are encouraging indicating that treatment with anticoagulation may be minimized safely following the Cox-maze procedure without increasing the risk of stroke or associated mortality, remaining consistent with our previous findings. ${ }^{27,28}$

We are pleased by the findings that suggest improved quality of life and reduced symptoms related to atrial fibrillation following the Cox-maze procedure. The assessment of quality of life is challenging, especially in this subgroup of patients who underwent a concomitant surgical procedure due to significant MV disease. A large part of their improvement in quality of life can be attributed to improved physiology related to valve surgery. In an attempt to improve our understanding regarding the potential effect of sinus rhythm restoration on quality of life, we used 2 different tools to measure the effect: the general Short Form-12 tool and an atrial fibrillation-specific tool to measure the frequency and severity of atrial fibrillation-related symptoms. Our findings suggest an improvement in the physical composite score of $\mathrm{HRQL}$, which increased significantly by 12 months, reaching age group norms and was correlated with specific atrial fibrillation symptom-related reduction. Part of this improvement is no doubt related to functional improvement as a result of their concomitant valve procedure(s). However, the high return to sinus rhythm rate by 12 months may also contribute to the influence on physical composite score of HRQL. In fact, in several recent publications, the return to sinus rhythm rate for patients in atrial fibrillation conveyed a significant increase in their quality of life similar to what was observed in our study. ${ }^{29-31}$ This is further supported by the results captured using an atrial fibrillation-specific questionnaire, which showed a significant decrease in symptoms associated with atrial fibrillation and corroborated the assertion that part of the increase in physical HRQL could be related to restoration of sinus rhythm.

Grigioni and colleagues ${ }^{32}$ determined that the risk to develop atrial fibrillation is about $15 \%$ to $21 \%$ over 5 years if conservative treatment is used to manage patients with functional MV disease and by 10 years $42 \%$ to $54 \%$ had developed atrial fibrillation. Moreover, atrial fibrillation was associated with high risk for cardiac death or heart failure (adjusted risk ratio, 2.23; $P=.025$ ) with the risk of atrial fibrillation increasing with age and left atrial size. The authors concluded that the clinical management of mitral regurgitation should take into account these factors and interventions should be directed to minimize the long-term consequences of untreated MV disease. Their findings together with the findings reported here are important when discussing with surgeons the negative effect of untreated atrial fibrillation following surgery and assists in advocating for performance-based education for more centers to be able to offer surgical ablation of atrial fibrillation when undergoing open heart surgery and especially MV or $\mathrm{MV}+\mathrm{TV}$ surgery to achieve optimal outcomes. Interestingly, patient risk and low surgeon experience were found to be significantly associated with not ablating atrial fibrillation in our study. Despite supportive evidence related to the potential benefit of surgical ablation for atrial fibrillation during MV surgery, the decision whether or not to perform the procedure is complex and dependent on surgeon experience and perception regarding the importance of atrial fibrillation. Several recent articles have investigated the successful use of simulation training in obtaining proficiency in certain surgical procedures. ${ }^{33-35}$ Simulation training in addition to sponsored fellowships in electrophysiology may be an avenue that can be developed to offer more opportunities for learning in a safe and economical way that will help expand centers that offer atrial fibrillation ablation surgery and improve patient outcomes and survival. National organizations such as the Heart Rhythm Society and the Society of Thoracic Surgeons may be well positioned to help lead this endeavor. We should develop a decision-making algorithm to optimize patient outcomes and address different aspects of atrial fibrillation from the control of the left atrial appendage to the full Cox-maze procedure. 


\section{Limitations}

This study was conducted at a very large volume cardiac surgical institute that performs more than 100 surgical ablation procedures and 400 valve surgeries annually and several surgeons have more than 50 cases of surgical ablation experience. Therefore, these results may not be generalizable to smaller volume centers without further training.

Data regarding rhythm and stroke/bleed events following surgery was only collected in the atrial fibrillation patients treated with the Cox-maze procedure. Although sinus rhythm was maintained in $86 \%$ of patients up to 24 months following surgery, without a comparison to the rhythm status of patients with untreated atrial fibrillation it is unclear from our analyses how much lower the expected return to sinus rhythm might be without the Cox-maze intervention. In addition, due to small sample size within the untreated atrial fibrillation group, the multivariate analyses should be viewed as exploratory analyses intended to prompt further research regarding these issues.

\section{CONCLUSIONS}

We conclude that patients who undergo MV or MV+TV surgery along with the Cox-maze procedure for atrial fibrillation can expect to have a high rate of return to sinus rhythm and similar survival compared with patients who undergo MV or MV+TV surgery in sinus rhythm. Attention should be directed toward addressing a patient's atrial fibrillation at the same time as his or her valve disease to improve patient outcomes. However, further educational opportunities through performance-enhanced training must be made available to surgeons so that patients will have access to this mode of atrial fibrillation treatment and associated outcomes.

\section{References}

1. Iung B, Vahanian A. Epidemiology of valvular heart disease in the adult. Nat Rev Cardiol. 2011;8:162-72

2. Gammie JS, Haddad M, Milford-Beland S, Welke KF, Ferguson TB Jr, O'Brien SM, et al. Atrial fibrillation correction surgery: lessons from the Society of Thoracic Surgeons National Cardiac Database. Ann Thorac Surg. 2008;85: 909-14.

3. Cox JL, Ad N, Palazzo T, Fitzpatrick S, Suyderhoud JP, DeGroot KW, et al. The Maze-III procedure combined with valve surgery. Semin Thorac Cardiovasc Surg. 2000;12:53-5

4. Chua YL, Schaff HV, Orszulak TA, Morris JJ. Outcome of mitral valve repair in patients with preoperative atrial fibrillation. Should the maze procedure be combined with mitral valvuloplasty? J Thorac Cardiovasc Surg. 1994;107: 408-15.

5. von Oppell UO, Masani N, O'Callaghan P, Wheeler R, Dimitrakakis G, Schiffelers S. Mitral valve surgery plus concomitant atrial fibrillation ablation is superior to mitral valve surgery alone with an intensive rhythm control strategy. Eur J Cardiothorac Surg. 2009;35:641-50.

6. Ad N, Cox JL. Combined mitral valve surgery and the Maze III procedure. Semin Thorac Cardiovasc Surg. 2002;14:206-9.

7. Lim E, Barlow CW, Hosseinpour AR, Wisbey C, Wilson K, Pidgeon W, et al. Influence of atrial fibrillation on outcome following mitral valve repair. Circulation. 2001;104(12 Suppl 1):I59-63.

8. Bando K, Kasegawa H, Okada Y, Kobayashi J, Kada A, Shimokawa T, et al. Impact of preoperative and postoperative atrial fibrillation on outcome after mitral valvuloplasty for nonischemic mitral regurgitation. $J$ Thorac Cardiovasc Surg. 2005;129:1032-40.

9. Wang B, Xu ZY, Han L, Zhang GX, Lu FL, Song ZG. Impact of preoperative atrial fibrillation on mortality and cardiovascular outcomes of mechanical mitral valve replacement for rheumatic mitral valve disease. Eur J Cardiothorac Surg. 2013;43:513-9.

10. Saint LL, Bailey MS, Prasad S, Guthrie TJ, Bell J, Moon MR, et al. Cox-Maze IV results for patients with lone atrial fibrillation versus concomitant mitral disease. Ann Thorac Surg. 2012;93:789-94; discussion 94-5.

11. Gillinov AM, Saltman AE. Ablation of atrial fibrillation with concomitant cardiac surgery. Semin Thorac Cardiovasc Surg. 2007;19:25-32.

12. Calkins H, Kuck KH, Cappato R, Brugada J, Camm AJ, Chen SA, et al. 2012 HRS/EHRA/ECAS expert consensus statement on catheter and surgical ablation of atrial fibrillation: recommendations for patient selection, procedural techniques, patient management and follow-up, definitions, endpoints, and research trial design. J Interv Card Electrophysiol. 2012;33:171-257.

13. Ad N, Henry L, Hunt S, Stone L. The implementation of a comprehensive clinical protocol improves long-term success after surgical treatment of atrial fibrillation. J Thorac Cardiovasc Surg. 2010;139:1146-52.

14. Damiano RJ Jr, Schwartz FH, Bailey MS, Maniar HS, Munfakh NA, Moon MR, et al. The Cox maze IV procedure: predictors of late recurrence. J Thorac Cardiovasc Surg. 2011;141:113-21

15. Cox JL. The surgical treatment of atrial fibrillation. IV. Surgical technique. J Thorac Cardiovasc Surg. 1991;101:584-92.

16. Ware J, Kosinski M, Turner-Bowker D, Gandek B. How to score version 2 of the SF-12 health survey. Lincoln, RI: Quality Metric Inc; 2002.

17. Jenkins L. Test specifications for the Bubien and Kay (revised Jenkins) symptom checklist: frequency and severity. Baltimore, Md: University of Maryland 1993

18. Ad N, Suri RM, Gammie JS, Sheng S, O’Brien SM, Henry L. Surgical ablation of atrial fibrillation trends and outcomes in North America. J Thorac Cardiovasc Surg. 2012;144:1051-60.

19. Bogachev-Prokophiev A, Zheleznev S, Romanov A, Pokushalov E, Pivkin A, Corbucci G, et al. Ablation for atrial fibrillation during mitral valve surgery: 1-year results through continuous subcutaneous monitoring. Interact Cardiovasc Thorac Surg. 2012;15:37-41.

20. Ghavidel AA, Javadpour H, Shafiee M, Tabatabaie MB, Raiesi K, Hosseini S Cryoablation for surgical treatment of chronic atrial fibrillation combined with mitral valve surgery: a clinical observation. Eur J Cardiothorac Surg. 2008;33: 1043-8.

21. Ngaage DL, Schaff HV, Barnes SA, Sundt TM 3rd, Mullany CJ, Dearani JA, et al Prognostic implications of preoperative atrial fibrillation in patients undergoing aortic valve replacement: is there an argument for concomitant arrhythmia surgery? Ann Thorac Surg. 2006;82:1392-9.

22. Ngaage DL, Schaff HV, Mullany CJ, Barnes S, Dearani JA, Daly RC, et al. Influence of preoperative atrial fibrillation on late results of mitral repair: is concomitant ablation justified? Ann Thorac Surg. 2007;84:434-42; discussion 42-3.

23. Ngaage DL, Schaff HV, Mullany CJ, Sundt TM 3rd, Dearani JA, Barnes S, et al. Does preoperative atrial fibrillation influence early and late outcomes of coronary artery bypass grafting? J Thorac Cardiovasc Surg. 2007;133:182-9.

24. Gage BF, Waterman AD, Shannon W, Boechler M, Rich MW, Radford MJ. Validation of clinical classification schemes for predicting stroke: results from the National Registry of Atrial Fibrillation. JAMA. 2001;285:2864-70.

25. Pet M, Robertson JO, Bailey M, Guthrie TJ, Moon MR, Lawton JS, et al. The impact of CHADS2 score on late stroke after the Cox maze procedure. J Thorac Cardiovasc Surg. 2013;146:85-9.

26. Lee R, Jivan A, Kruse J, McGee EC Jr, Malaisrie SC, Bernstein R, et al. Late neurologic events after surgery for atrial fibrillation: rare but relevant. Ann Thorac Surg. 2013;95:126-31; discussion 31-2.

27. Ad N, Henry L, Schlauch K, Holmes SD, Hunt S. The CHADS score role in managing anticoagulation after surgical ablation for atrial fibrillation. Ann Thorac Surg. 2010;90:1257-62

28. Cox JL, Ad N, Palazzo T. Impact of the maze procedure on the stroke rate in patients with atrial fibrillation. J Thorac Cardiovasc Surg. 1999;118:833-40.

29. Ad N, Henry L, Hunt S. The concomitant cryosurgical Cox-Maze procedure using Argon based cryoprobes: 12 month results. J Cardiovasc Surg (Torino). 2011; $52: 593-9$.

30. Camm J. Antiarrhythmic drugs for the maintenance of sinus rhythm: risks and benefits. Int J Cardiol. 2012;155:362-71.

31. Saliba W, Wazni OM. Sinus rhythm restoration and treatment success: insight from recent clinical trials. Clin Cardiol. 2011:34:12-22. 
32. Grigioni F, Avierinos JF, Ling LH, Scott CG, Bailey KR, Tajik AJ, et al. Atrial fibrillation complicating the course of degenerative mitral regurgitation: determinants and long-term outcome. J Am Coll Cardiol. 2002;40:84-92.

33. Andersen DK. How can educators use simulation applications to teach and assess surgical judgment? Acad Med. 2012;87:934-41

34. Kanter SL. The need for more sophisticated simulation applications to teach and assess expert judgment. Acad Med. 2012;87:833.

35. Pugh CM, DaRosa DA, Santacaterina S, Clark RE. Faculty evaluation of simulation-based modules for assessment of intraoperative decision making. Surgery. 2011;149:534-42.

\section{Discussion}

Dr Vinay Badhwar (Pittsburgh, Pa). This is another fine contribution to guide surgical decision making when faced with atrial fibrillation (AF) at the time of mitral valve operations. This retrospective analysis of prospectively collected data of 208 propensity-matched pairs of patients receiving mitral surgery and the Cox-MAZE IV procedure when AF was present versus mitral surgery alone when it was not. This important work provides us with clear level II(a) evidence that the addition of a concomitant Cox-maze IV procedure during mitral surgery is safe and not associated with any negative effect on short- or midterm outcomes.

Consistent with the recent literature, this study's Cox proportional hazards regression comparison of 236 unmatched patients with AF presenting for mitral surgery who received the maze procedure versus 75 who did not, also confirms clear short- and midterm survival advantage associated with the maze operation.

I have 3 questions to help us interpret this important data, which I will ask in sequence giving you time to respond.

Number 1: In the 75 patients with AF who did not undergo maze procedure, how many of these were nonparoxysmal?

Dr Niv Ad (Falls Church, Va). That is an excellent question. Two groups of untreated and treated patients actually came, the same distribution of the type of AF.

Dr Badhwar. Number 2: These 75 patients were actually older, had lower ejection fractions, and a higher preoperative risk profile as measured by European System for Cardiac Operative Risk Evaluation (EuroSCORE). Given the cohort size difference in the maze versus no maze regression analyses, bias included, how do you reconcile the influence of preoperative risk on the interpretation of the Kaplan-Meier survival curves? In other words, tomorrow when we are faced with an elderly high-risk patient with a low ejection fraction presenting for mitral surgery, are you convinced that this data provides us the support that the addition of a maze operation at the time of mitral replacement or repair is warranted?

Dr Ad. Well, that sums everything. It is the decision making. We are working a lot on understanding decision making related to surgical ablation of AF. We created a clinical algorithm of risk scores combined with surgeon's experience in surgical ablation to test and better understand what influences the decision the most. An upcoming publication will cover this.

To put it simply, what type of concomitant problem the patient has and how sick the patient is. In other words, what do we think in our own minds that the 5-year survival of the patient is going to be? Also, how complex is the surgery going to be if we add the surgical ablation procedure? In other words, how long does it take you to add the maze procedure to a mitral valve replacement or repair (it doesn't take long if you are doing it a lot)? I am looking all the time at right ventricle function. If the right ventricle is relatively dysfunctional, then my threshold to perform the procedure is going to be very low.

Dr Badhwar. We know that the effective technical performance of the Cox-maze IV operation relies on one's knowledge of energy sources and the lesion set; in other words, experience. So as a maze procedure expert in your institution, what proportion of those 311 cases presenting for mitral surgery with AF did you do personally-approximately $76 \%$ ? Expecting my hypothesis might be close, perhaps this is simply a provocative way of asking what role our professional societies and the device industry should play in surgical education of the maze procedure now that global evidence continues to mount as to longitudinal outcome benefits associated with concomitant surgical ablation?

Dr Ad. I think it is an excellent point, but I think the biggest question is not my personal contribution to this series. I can give you the numbers: I did 175 out of 236 ablations and only 4 out of 75 in the untreated group. Clearly I am more aggressive in applying the maze procedure in my patients.

I believe that the biggest message is how can someone with more experience within a group of surgeons - and this applies to any type of surgery not just for AF-can convey a solid message to their other partners. There are 2 different types of surgeons: those who are more experienced than you are and they know and have seen everything before you and, therefore, it is very difficult to change them, and those who are younger and reluctant to increase the complexity of the procedure and by so doing may increase morbidity.

My role right now is to convey a message that it is safe and can be done appropriately, it can be staged, and maybe I can assist them in part of the cases so younger surgeons-as well as more veteran ones who are willing to learn-are shown how to do it appropriately and will apply the procedure to many more eligible patients.

Dr Badhwar. So that this data provides us with a call to action to further promote surgical education of surgical ablation?

Dr Ad. Yes.

Dr Patrick M. McCarthy (Chicago, Ill). I have some short, specific questions. How did you handle the left atrial appendage in the 2 groups, and do you know the late stroke risk in the groups?

Dr Ad. For the open cases, until recently (I don't have the cutoff dates) I think in a little more than 210 patients the appendage was basically cut and oversewn. There are not any other devices. Lately we started to use with much success the AtriClip (AtriCure, Inc, West Chester, Ohio), which we are very happy with. These are the 2 major modes.

As for the AF group, unfortunately, and this is something we are working hard on, only in 4 out of 75 patients the appendage was managed. This is a gap that we have to close, and I think that now it is clear that no patients with AF, whether they have AF surgery or not, should leave the operating room with the left atrial appendage not being closed. We don't have the data about the late stroke rate for the untreated group.

Dr McCarthy. Another quick question: How do you handle discontinuing warfarin and do you use scores like CHADS, or CHA2 DS2 VASc to help decide?

Dr Ad. We put all patients, unless there is a contraindication, on warfarin. Our time to stop warfarin is 6 months, because I think 
there is a lot of background noise around 3 months, and if you try to stop it at 3 months it is kind of unrealistic. Patients' antiarrhythmia drugs are being stopped at 3 months if they are in sinus rhythm, and they are being monitored at 6 months, and if the patients are found to be in sinus rhythm, we perform echocardiography, and if the appendage is eliminated and there is no smoke in the left atrium, in other words, the flow seems to be okay regardless of A-waves in the left atrium, we stop the warfarin. We don't really look into the CHADS score, and we actually published an excellent article a while back that showed that the CHADS score is irrelevant in this subgroup of patients.

Dr A. Marc Gillinov (Cleveland, Ohio). Everybody in this series had a biatrial lesion set, a Cox-maze III or IV. What would you say to the surgeon who says, okay, I am going to perform ablations, but I am only going to do pulmonary vein isolation?

Dr Ad. I don't think it's a good idea, even in the paroxysmal setup, because we don't know enough about the effects of paroxysmal AF on the other parts of the atrium; for example, can it be originated outside the pulmonary veins or not? We know it's a long discussion. So I would definitely recommend considering the biatrial Cox-maze lesion set in all patients unless there are issues that should be dealt with to avoid it.

Dr Harold G. Roberts (Lauderdale Lakes, Fla). Were any of the failures perhaps related to assessment of left atrial size? Have you found that if you do have a large left atrium that reduction has any role in increasing the success?

Dr Ad. In our multivariate models we never found atrial size as an independent predictor in a multivariate model for failure. The only predictor for failure in our multivariate model that is consistent is duration of AF before surgery. There is a slight decrease in success rate as you go into the larger size of atrium, but $16 \%$ of patients had left atrial size $>6 \mathrm{~cm}$. So we are not talking about giant atria. I don't think we have enough evidence to support left atrial reduction, we don't have time to discuss it here, but I am not doing left atrium reduction surgery besides cutting out the left atrial appendage. 